\title{
Sapindaceae endémicas del Perú
}

\section{Blanca León ${ }^{1,2}$}

${ }^{1}$ Museo de Historia Natural, Av. Arenales 1256, Aptdo 14-0434, Lima 14, Perú

${ }^{2}$ Plant Resources Center, University of Texas at Austin, Austin TX 78712 EE.UU.

blanca.leon@mail.utexas.edu

\section{Resumen}

La familia Sapindaceae es reconocida en el Perú por presentar 22 géneros y alrededor de 190 especies (Brako \& Zarucchi, 1993; Ulloa Ulloa et al., 2004), principalmente lianas, árboles y bejucos. En este trabajo reconocemos 16 especies y una variedad como endemismos en siete géneros. Paullinia es el género más rico en especies. Los taxones endémicos se encuentran principalmente en las regiones Bosques Húmedos Amazónicos, Bosques Muy Húmedos Montanos y Bosques Muy Húmedos Premontanos, entre los 100 y $2900 \mathrm{~m}$ de altitud. Cuatro especies endémicas se encuentran representadas dentro del Sistema Nacional de Áreas Naturales Protegidas por el Estado.

Palabras claves: Sapindaceae, Paullinia, Perú, endemismo, plantas endémicas.

\section{Abstract}

The Sapindaceae are represented in Peru by 22 genera and around 190 species (Brako \& Zarucchi, 1993; Ulloa Ulloa et al., 2004), mainly lianas, trees and vines. Here we recognize 16 species and one variety as endemics in seven genera. Paullinia is the genus with more endemic species. Endemic taxa are found in Humid Lowland Amazonian Forests, Very Humid Montane Forests and Very Humid Premontane Forests regions, between 100 and 2900 m elevation. Four endemic Sapindanceae species have been recorded within Peru's protected areas system.

Keywords: Sapindaceae, Paullinia, Peru, endemism, endemic plants.

\section{Allophylus densiflorus Radlk.}

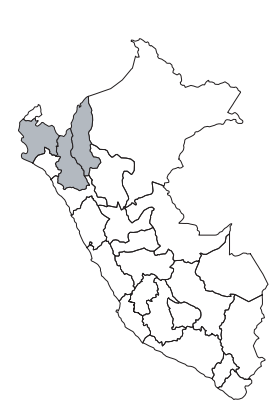

\section{DD}

Publicación: Sitzungsber. Math.-Phys. Cl. Konigl. Bayer. Akad. Wiss. Munchen 38: 211. 1909.

Colección tipo: A. Mathews s.n.

Herbarios: G.

Nombre común: Desconocido.

Registro departamental: AM, CA, PI.

Regiones Ecológicas: BMHM; 1400$2900 \mathrm{~m}$.

SINANPE: Sin registro.

Herbarios peruanos: CPUN (1).

Observaciones: Bejuco descrito de una planta recolectada en el nororiente del país, en el siglo XIX. Esta especie es conocida también de otras tres localidades, incluyendo las vertientes del Pacífico. Se desconoce el estado actual de sus poblaciones.

\section{Allophylus multicostatus A.H. Gentry}

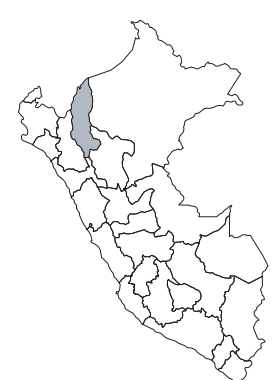

\section{DD}

Publicación: Novon 2(4): 337. 1992. Colección tipo: B. Berlin 346 Herbarios: MO.

Nombre común: Desconocido.

Registro departamental: AM.

Regiones Ecológicas: BHA; $185 \mathrm{~m}$.

SINANPE: ZRSC

Herbarios peruanos: Ninguno.

Observaciones: Árbol conocido aparentemente sólo de la colección tipo, una planta procedente de la cuenca del Cenepa, recolectada en 1972. Esta localidad está ubicada en la Zona Reservada SantiagoComaina. Se desconoce el estado actual de sus poblaciones.

\section{Melicoccus petiolulatus Acev.-Rodr.}

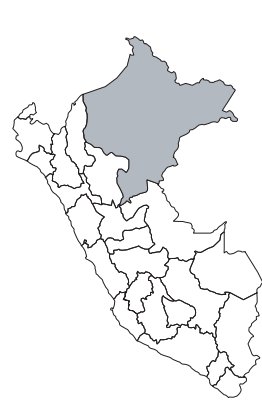

DD

Publicación: Fl. Neotrop. 87: 32, 34, f. 26a-c. 2003.

Colección tipo: E.P. Killip \& A.C. Smith 27762

Herbarios: US

Nombre común: Desconocido.

Registro departamental: LO.

Regiones Ecológicas: BHA; $135 \mathrm{~m}$.

SINANPE: Sin registro.

Herbarios peruanos: Ninguno.

Observaciones: Especie arbustiva, conocida de dos localidades cercanas, en la cuenca del Huallaga. Al parecer, no ha vuelto a ser recolectada desde 1929, probablemente, a lo poco herborizada que ha sido esa parte del país. Se desconoce el estado actual de sus poblaciones.

\section{Paullinia enneaphylla G. Don}

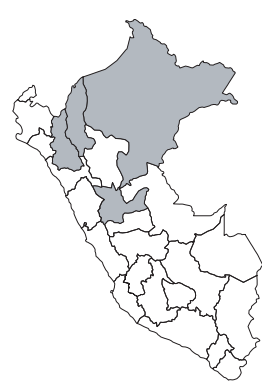

$$
\text { VU, B1ab(iii) }
$$

Publicación: Gen. Hist. 1: 662. 1831. Colección tipo: H. Ruiz \& J. Pavón 12/18 Herbarios: MA.

Nombre común: Desconocido. Registro departamental: AM, CA, HU, LO.

Regiones Ecológicas: BMHM, BMHP, BHA; $120-2000 \mathrm{~m}$.

SINANPE: RNAM

Herbarios peruanos: Ninguno.

Observaciones: Esta liana se conoce de varias localidades, en un amplio rango de ambientes y altitudes. Sus poblaciones ocupan los bosques perennifolios de la vertiente del Pacífico en la cuenca del Chotano, asi como la Amazonía peruana, cuencas del Huallaga y Amazonas. La deforestación es la principal amenaza. 


\section{Paullinia fistulosa Radlk.}

\section{DD}

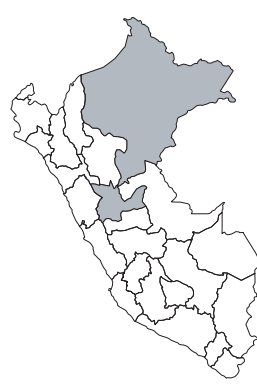

Publicación: Monogr. Paullinia 259. 1895. Colección tipo: F. de Castelnau s.n.

Herbarios: P.

Nombre común: Desconocido.

Registro departamental: HU, LO.

Regiones Ecológicas: BHA; altitud desconocida.

SINANPE: Sin registro.

Herbarios peruanos: Ninguno.

Observaciones: Liana conocida, al parecer, de dos localidades en la Amazonía peruana. Es probable, que esté representada en la flora de Ecuador. Se desconoce el estado actual de sus poblaciones.

\section{Paullinia killipii J.F. Macbr.}

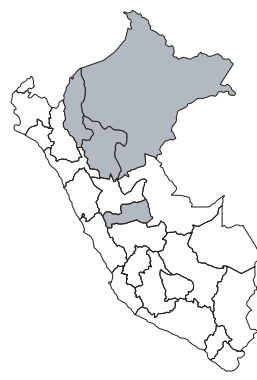

$$
\text { VU, B1a }
$$

Publicación: Field Mus. Nat. Hist., Bot. Ser. 13(3A/2): 344. 1956.

Colección tipo: E.P. Killip \& A.C. Smith 26383

Herbarios: F, NY, US.

Nombre común: Naek.

Registro departamental: AM, LO, PA, SM. Regiones Ecológicas: BHA; 190—680 m. SINANPE: Sin registro.

Herbarios peruanos: AMAZ (1).

Observaciones: Liana conocida de varias localidades en el oeste de la Amazonía peruana, en las cuencas del Mayo, Huallaga, Pastaza, Pichis, entre otros.

\section{Paullinia linearis Radlk.}

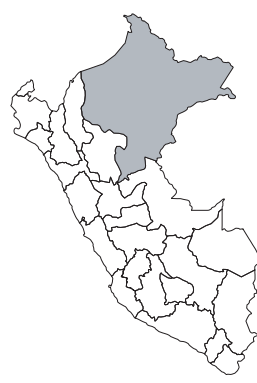

\section{DD}

Publicación: Monogr. Paullinia 223. 1895. Colección tipo: E.F. Poeppig s.n. Herbarios: W.

Nombre común: Desconocido.

Registro departamental: LO.

Regiones Ecológicas: BHA; $140 \mathrm{~m}$.

SINANPE: Sin registro.

Herbarios peruanos: Ninguno.

Observaciones: Liana conocida, al parecer, de dos colecciones provenientes del occidente de la Amazonía peruana. El ejemplar tipo fue recolectado en 1831, en la cuenca del Huallaga. Se desconoce el estado actual de sus poblaciones.

\section{Paullinia martinensis Cuatrec.}

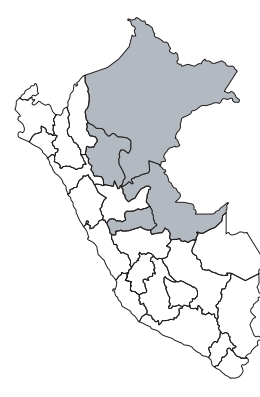

\section{DD}

Publicación: Fieldiana, Bot. 27(2): 82. 1951.

Colección tipo: F. Woytkowski 35160

Herbarios: F, MO.

Nombre común: Desconocido.

Registro departamental: LO, PA, SM, UC. Regiones Ecológicas: BMHP, BHA; 161-830 m.

SINANPE: Sin registro.

Herbarios peruanos: USM (1).

Observaciones: Liana conocida de varias localidades en el nor y centro oriente del país. Es conocida de las cuencas del Huallaga, Pachitea y Ucayali. Se desconoce el estado actual de sus poblaciones.
9. Paullinia obovata (Ruiz \& Pav.) Pers. subsp. flava Weckerle \& Igersheim

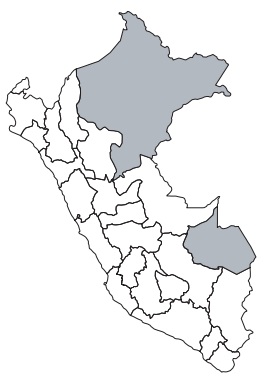

\section{EN, B1a}

Publicación: Novon 13(1): 149, f. 3A, B. 2003.

Colección tipo: A. Vásquez et al. 000527$1 / 4$

Herbarios: Z; MOLF.

Nombre común: Desconocido.

Registro departamental: LO, MD.

Regiones Ecológicas: BHA; $100 \_400 \mathrm{~m}$.

SINANPE: Sin registro.

Herbarios peruanos: MOLF (holotipo+1), USM (6).

Observaciones: Liana conocida de varias localidades en la Amazonía. Este taxón podría tratarse de un especialista de bosques inundables. Se le conoce de localidades distantes más de $900 \mathrm{~km}$.

\section{Paullinia tenera Poepp.}

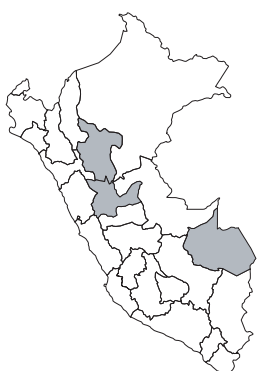

DD

Publicación: Nov. Gen. Sp. Pl. 3: 37, t. 243. 1844.

Colección tipo: E.F. Poeppig 1090

Herbarios: NY, W.

Nombre común: Desconocido.

Registro departamental: HU, MD, SM.

Regiones Ecológicas: BMHP; $600 \mathrm{~m}$.

SINANPE: PNM

Herbarios peruanos: Ninguno.

Observaciones: Liana conocida de localidades dispersas, en las cuencas del Huallaga y Alto Madre de Dios. Se desconoce el estado actual de sus poblaciones.

\section{Serjania brachyptera Radlk.}

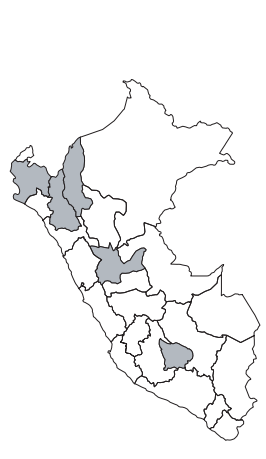

\section{VU, B1a}

Publicación: Bot. Jahrb. Syst. 37: 145. 1905.

Colección tipo: A. Weberbauer 3304

Herbarios: B; MOL!

Nombre común: Desconocido.

Registro departamental: AM, AP, CA, HU, PI.

Regiones Ecológicas: MA; 2600—3700 m. SINANPE: Sin registro.

Herbarios peruanos: CPUN (1), HAO (1), MOL (isotipo).

Observaciones: Liana descrita de una planta recolectada en 1903, del Callejón de Conchucos, cuenca del Marañón. Es conocida también de la vertiente del Pacífico, cuenca del Chicama y Magdalena, así como de la cuenca interandina de Huancabamba.

\section{Serjania fuscostriata Radlk.}

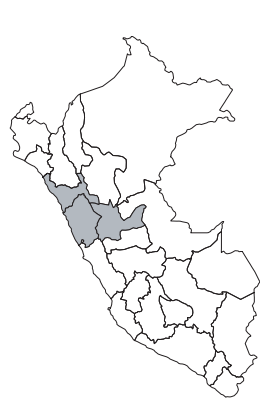

\section{NE}

Publicación: Bot. Jahrb. Syst. 37: 147. 1905.

Colección tipo: A. Weberbauer 3183

Herbarios: B.

Nombre común: Desconocido.

Registro departamental: AN, HU, LL.

Regiones Ecológicas: MDE; $1900 \mathrm{~m}$.

SINANPE: Sin registro.

Herbarios peruanos: Ninguno. 
Observaciones: Arbusto escandente, descrito de una planta de la vertiente del Pacífico. Macbride (1956) señaló el vínculo estrecho entre esta especie y Serjania brachyptera, otra especie endémica descrita de la cuenca del Marañón, sin embargo, falta aclarar este vínculo.

\section{Serjania peruviana Radlk.}

\section{DD}

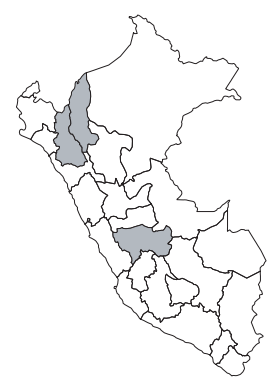

Publicación: Monogr. Serjania 154. 1886. Colección tipo: A. Mathews 3094

Herbarios: K.

Nombre común: Desconocido.

Registro departamental: AM, CA, JU.

Regiones Ecológicas: BMHM; altitud desconocida.

SINANPE: Sin registro.

Herbarios peruanos: Ninguno.

Observaciones: Liana conocida de localidades dispersas, en las cuencas del Mantaro, Marañón y Chinchipe. Se desconoce el estado actual de sus poblaciones.

\section{Serjania striata Radlk.}

\section{EN, B1ab(iii)}

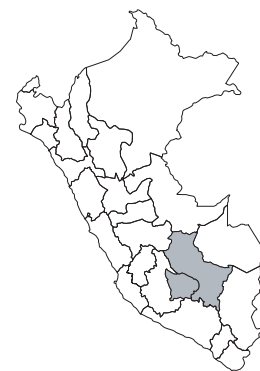

Publicación: Monogr. Serjania 280. 1875.

Colección tipo: C. Gay s.n.

Herbarios: M, P.

Nombre común: Desconocido.

Registro departamental: AP, CU.

Regiones Ecológicas: MA; 1950—2600

m.

SINANPE: Sin registro.

Herbarios peruanos: Ninguno.

Observaciones: Arbusto escandente, conocido al parecer, de unas pocas localidades, en las cuencas del Pachachaca, Vilcanota y Apurímac. Esta especie está asociada a matorrales, impactados por las quemas intencionales.

\section{Serjania striolata Radlk.}

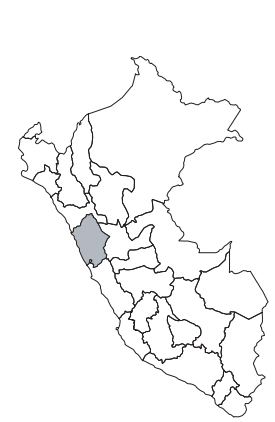

\section{CR, B1ab(iii)}

Publicación: Bot. Jahrb. Syst. 37: 147. 1905.

Colección tipo: A. Weberbauer 3031

Herbarios: B; MOL!.

Nombre común: Desconocido.

Registro departamental: AN.

Regiones Ecológicas: MA; 2200-3700

m.

SINANPE: Sin registro.

Herbarios peruanos: MOL (isotipo)..

Observaciones: Liana conocida, al parecer, sólo de la colección tipo, una planta recolectada en 1903, de fragmentos de bosque andino, entre la cuenca del Santa y la Cordillera Negra. Los ambientes propicios para esta especie podrían estar afectados por incendios intencionales asociados a las actividades agrícolas.
16. Talisia pinnata (Ruiz \& Pav.) Radlk.

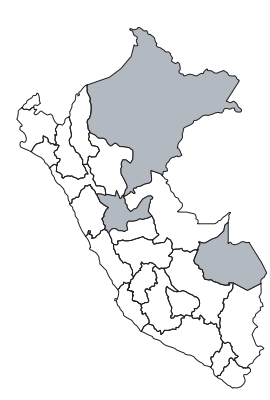

$$
\text { VU, B1a }
$$

Publicación: Sitzungsber. Math.-Phys. Cl. Konigl. Bayer. Akad. Wiss. Munchen 8:351. 1878.

Colección tipo: J. Pavón s.n.

Herbarios: BM, MA.

Nombre común: Desconocido.

Registro departamental: HU, LO, MD.

Regiones Ecológicas: BHA; $120-200 \mathrm{~m}$. SINANPE: RNPS

Herbarios peruanos: AMAZ (1), USM (3).

Observaciones: Árbol conocido de las cuencas del Huallaga, Madre de Dios, Nanay y Ucayali. En la base de datos TROPICOS, el ejemplar ecuatoriano atribuido a esta especie, corresponde a Talisia setigera restringida a ese país. El taxón peruano cuenta con poblaciones en un área protegida privada (Cuzco Amazónico).

\section{Urvillea peruviana Ferrucci}

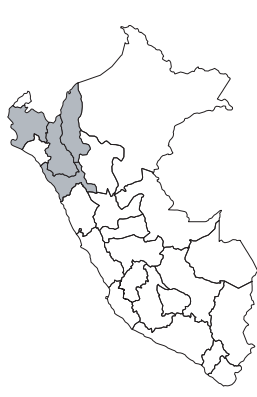

\section{DD}

Publicación: Bonplandia 9(3-4): 237. 1997.

Colección tipo: M.S. Ferrucci et al. 1112 Herbarios: AAU, CTES, F, G, GH, K, LIL, LPB, MEXU, MICH, MO, NY, QCA, SI, TEX, U, US, USZ; HAO!, HUT, USM.

Nombre común: Desconocido.

Registro departamental: AM, CA, LL, PI. Regiones Ecológicas: BS; 860-950 m. SINANPE: Sin registro.

Herbarios peruanos: HAO (holotipo), HUT (isotipo citado), USM (isotipo citado).

Observaciones: Bejuco, al parecer, conocido sólo de las cuencas del Chamaya, Huancabamba y Marañón. Esta especie habita ambientes semixéricos. Se desconoce el estado actual de sus poblaciones. 